\title{
Normal values of esophageal high-resolution manometry: a Brazilian multicenter study
}

\author{
Gerson Ricardo DOMINGUES ${ }^{1}$, Nelson Henrique MICHELSOHN ${ }^{2,3}$, Ricardo Guilherme VIEBIG4, \\ Décio CHINZON ${ }^{5}$, Ary NASI ${ }^{3,6}$, Carla Granja ANDRADE7, Eponina Maria LEMIME ${ }^{8}$, Luiz João ABRAHÃO JUNIOR ${ }^{8}$, \\ Mauricio Gustavo BRAVIM ${ }^{9}$, Miguel Ângelo NOBRE-E-SOUZA ${ }^{10}$, Nayara Salgado CARVALHO ${ }^{11}$, \\ Paulo J P C CARVALHO11, Tomás Navarro RODRIGUES ${ }^{12}$ and Joaquim Prado P MORAES FILHO13
}

ABSTRACT - Background - The high-resolution manometry has been a significant advance in esophageal diagnostics. There are different types of catheter and systems devices to capture esophageal pressures that generate variable data related to Chicago Classification (CC) and consequently influence normal values results. There are not normative data for the 24-channel water-perfused high-resolution manometry system most used in Brazil with healthy volunteers in supine posture. Objective - To determine manometric esophageal normative values for a 24-channel water-perfused high-resolution manometry catheter in supine posture using healthy volunteers according to CC 3.0 parameters. Methods - A total of 92 volunteers with no gastrointestinal symptoms or medications affecting GI motility underwent esophageal high-resolution manometry by standard protocol. Age, gender and manometry parameters analyzed using Alacer software were collected. The median, range, and 5th and 95th percentiles (where applicable) were obtained for all high-resolution manometry metrics. Normal value percentiles were defined as 95th integrated relaxation pressure, 5th-100th distal contractile integral, and 5th distal latency. Results - The mean age was $40.5 \pm 13.2$ years. Our normative metrics were integrated relaxation pressure $<16 \mathrm{mmHg}$ and distal contractile integral $(708-4111 \mathrm{mmHg} . \mathrm{cm} . \mathrm{s})$ distal latency was $<6 \mathrm{~s}$ and peristaltic break size $(>4.0 \mathrm{~cm})$. For EGJ-CI the range 5th-95th was 21.7-86.9 mmHg.cm.s. Conclusion - This is the first report of normative data for the 24-channel water-perfused system in supine posture. It revealed higher integrated relaxation pressure and distal latency duration which suggest the need to change CC 3.0 cutoffs for this system. It is observed that there is a tendency that DCI $>7000 \mathrm{mmHg} . \mathrm{cm} . \mathrm{s}$ may represent the lower limit of hypercontractility, and when $<700 \mathrm{mmHg} . \mathrm{cm} . \mathrm{s}$ $(<5 \%$ percentile) interpreted as ineffective esophageal motility or failcontraction. Also compared to Chicago 3.0, higher integrated relaxation pressure and duration of distal latency were found. We emphasize that these data must be confirmed by future studies.

HEADINGS - Esophagus. Gastrointestinal motility. Manometry. Peristalsis. Reference values.

\section{Keypoints}

- Chicago Classification 3.0 metrics were derived from solid-state catheters. Brazilian multicenter normative data using a 24-channel water-perfused high-resolution manometry catheter is not available.

- Pressure-dependent Chicago Classification metrics, integrated relaxation pressure, distal latency and distal contractile integral are higher with the 24-channel water-perfused system.

- This is the first multicenter study reporting esophageal normal values for the 24-channel water-perfused high-resolution manometry system widely used in Brazil.

\section{INTRODUCTION}

Esophageal motility evaluation has long been an important tool to clarify patient's motor esophageal symptoms. More recently, the introduction of high-resolution manometry (HRM) has made important changes in the understanding of pathophysiologic mechanisms and allowed the creation of sophisticated analysis algorithms, placing this diagnostic method to a new level ${ }^{(1)}$. Actually, it provides image-based manometric interpretation with significant advantages over conventional manometry and, in addition, HRM has also been proved friendly use, easy to learn, improved patient comfort and diagnostic yield ${ }^{(1)}$.

Two types of HRM systems are currently available: water-perfused HRM and solid-state $\mathrm{HRM}^{(2)}$. Both systems have more and closer pressure sensors than the conventional manometry, and the pressure topography used in the HRM gives detailed information of the whole esophagus and parts of the pharynx and the stomach. However, HRM data derived from both systems may vary and are influenced and depend on the perfusion rate, catheter diameter and solid-state sensors that has electronic pressure sensors within the catheter itself ${ }^{(3)}$.

Declared conflict of interest of all authors: none

Disclosure of funding: no funding received

All authors are from Brazilian Working Group for Esophageal High Resolution Manometry.

Universidade do Estado do Rio de Janeiro, Departamento de Medicina Interna, Disciplina de Gastroenterologia, Rio de Janeiro, RJ, Brasil. ${ }^{2}$ Centro de Motilidade Digestiva (CDM), São Paulo, SP, Brasil. Fleury Medicina e Saúde, Departamento de Motilidade, São Paulo, SP, Brasil. ${ }^{4}$ Instituto Brasileiro de Estudos e Pesquisas de Gastroenterologia e Especialidades (IBEPEGE), Motilidade Digestiva e Neurogastroenterologia (MoDiNe) São Paulo, SP Brasil ${ }^{5}$ Universidade de São Paulo, Faculdade de Medicina, Hospital das Clínicas, São Paulo, SP Brasil. ${ }^{6}$ Universidade de São Paulo, Departamento de Motilidade, São Paulo, SP, Brasil. ${ }^{7}$ CGA Centro Especializado em Neurogastroenterologia e Motilidade Digestiva, São Paulo, SP, Brasil. ${ }^{8}$ Universidade Federal do Rio de Janeiro, Hospital Universitário Clementino Fraga Filho, Clínica Médica, Rio de Janeiro, RJ, Brasil. ${ }^{9}$ Centro de Motilidade do Aparelho Digestivo (CEMAD), Belo Horizonte, MG, Brasil. ${ }^{10}$ Universidade Federal do Ceará, Faculdade de Medicina, Fortaleza, CE, Brasil. ${ }^{11}$ Hospital Israelita Albert Eisntein, Núcleo de Fisiologia Gastrointestinal (NUFIG), São Paulo SP, Brasil. ${ }^{12}$ Universidade de São Paulo, Faculdade de Medicina, Hospital das Clínicas, Serviço de Gastroenterologia e Hepatologia Clínica, São Paulo, SP, Brasil. ${ }^{13}$ Universidade de São Paulo, Faculdade de Medicina, Departamento de Gastroenterologia São Paulo, SP, Brasil.

Corresponding author: Gerson Domingues. E-mail: gersondomingues62@gmail.com 
Using different HRM systems, investigators have been trying to set up a reasonable and systemic criterion for the diagnosis of the esophageal motility diseases ${ }^{(3)}$. Meanwhile, the closer pressure sensors allow HRM systems provide more detailed and precise manometry results than conventional manometry systems ${ }^{(4)}$. Thus, with the use of this technique, an HRM solid-state catheter was developed that showed a high level of detail at the esophagogastric junction (EGJ) and the esophagus by using 36 pressure sensors. The currently available solid-state HRM catheters often use circumferential pressure sensors, and it has been suggested that those pressure sensors increase the accuracy of measuring the pressure of the asymmetric EGJ ${ }^{(5)}$. Furthermore, the response rate of solidstate manometry is considerably higher.

Normal HRM values for Western populations, in particular North Americans, were first established for the solid-state system and a new classification, Chicago Classification (CC) $)^{(5)}$ was developed. Solid-state HRM features an easier system setup and faster response rates than water-perfused HRM systems, but from a practical point of view, the cost of solid state HRM devices poses a limitation for its generalized use ${ }^{(6)}$. Water-perfused HRM systems are still frequently used in many European, Asian Pacific, and South America countries because of their better durability and the lower cost of the catheter and associated pressure transduction system ${ }^{(6)}$. Although perfusion catheters require considerable preparation time, the new catheters that have recently been developed, obtaining pressure measurements, have quality comparable to solid-state $\mathrm{HRM}^{(7,8)}$. Normal values for water-perfused HRM for the Western population have thus also been established with only slight differences from the previously published values for solid-state $\mathrm{HRM}^{(8)}$.

The solid-state manometry catheter is currently considered the gold standard for esophageal HRM, and the normal values presented in CC have therefore been developed specifically for the use of solidstate catheters ${ }^{(9,10)}$. Currently, several different HRM systems are commercially available and new types of catheters are being developed as the clinical importance of esophageal manometry is now clearly established. In this way, normative values for esophageal HRM using different systems are important and needed. However, today, these data are still scarse. The International High-Resolution Manometry Working Group recommends that CC parameter normative values be determined for each system and population, with modification if different from their recommendation ${ }^{(10)}$.

In view of the above considerations, the aim of the present study was to establish normal reference values for the 24-channel waterperfused HRM system in a sample of the Brazilian population.

To obtain an expressive result, the Brazilian Working Group for
Esophageal High-Resolution Manometry was constituted and carried out this project under the supervision of the Brazilian Society of Digestive Motility and Neurogastroenterology.

\section{METHODS}

\section{Study subjects}

This prospective study on healthy volunteers was a multicenter study that enrolled eight Brazilian known gastrointestinal motility units, between January 2018 and June 2019.

The project received approval from Hospital Universitário Pedro Ernesto (UERJ) Research Ethics Committee under the reference of CAAE 07672818.7.0000.5259.

The healthy asymptomatic volunteers aged $\geq 18$ years were recruited among hospital employees ranging from domestic staff to doctors/senior managers as well as non-hospital volunteers. All signed a written informed consent for study participation before undergoing the test.

The exclusion criteria were as follow:

- No history of digestive disorders and no other illnesses, such as systemic sclerosis, diabetes mellitus, connective tissue diseases, liver cirrhosis, malignancy.

- No gastrointestinal symptoms in the previous six months.

- Recent ingestion of medications that may affect gastrointestinal motility such as calcium channel blockers, nitrates, domperidone or opioids.

- Use of anticoagulants or antiplatelets in one week prior to enrollment in the study.

- History of acute inflammation or stricture or obstruction of the nasal cavity or esophagus.

\section{Equipment}

All studies were performed with Alacer Multiplex System which consists:

A 24-channel water-perfused PVC esophageal catheter of $4.7 \mathrm{~mm}$ in outer diameter was used. The esophageal catheter includes 24 pressure channels distributed along the catheter. Each channel is connected to an external transducer that registers pressure changes.

A continuous flow of water with constant pressure and speed is generated through the catheter by a perfusion pump. The luminal diameter of each perfusion channel was $0.43 \mathrm{~mm}$, oriented spirally, with 10 sensors spaced at $0.7 \mathrm{~cm}$ placed in the zone recording the EGJ and spaced $2 \mathrm{~cm}$ apart in the areas of the esophageal body, covering a total length of $34 \mathrm{~cm}$ (FIGURE 1).

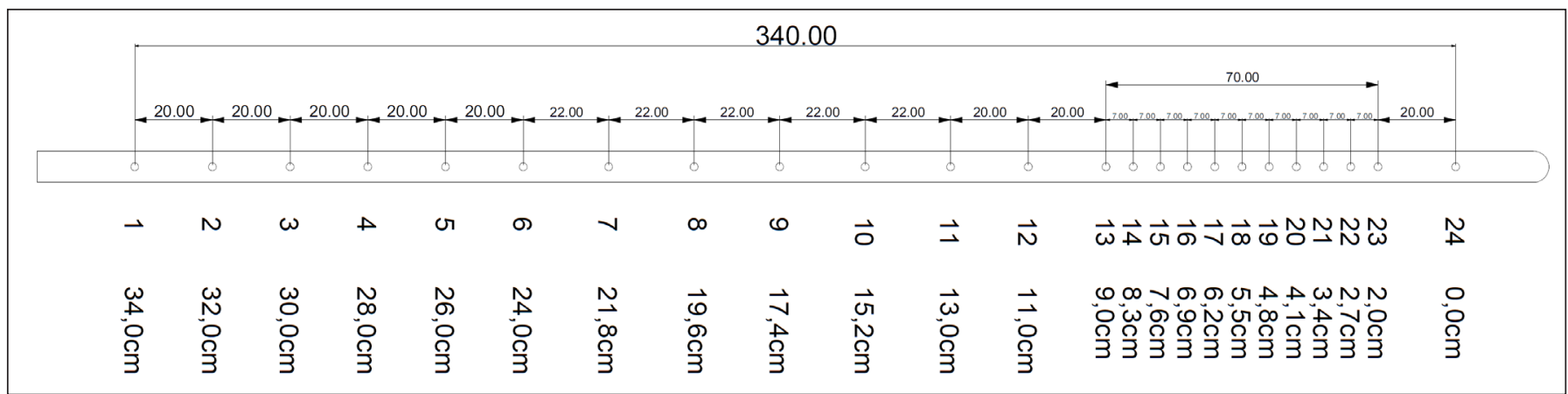

FIGURE 1. Schematic representation of water-perfused high-resolution manometry catheter with the spiral configuration of the pressure sensors to measure esophagogastric junction. 
Data obtained through this system was later analyzed with a dedicated software (Alacer HRM - Alacer Biomédica Indústria Eletrônica, São Paulo, Brazil). This allows to measure the EGJ relaxation with all its components (lower esophageal sphincter (LES), crural diaphragm, intrabolus pressure) and body of the esophagus contractility ${ }^{(6)}$.

\section{Study protocol}

All participants provided basic demographic information and were interviewed by a gastroenterologist. After an $\geq 4$ hour fast and a detailed explanation and reassurance regarding the procedure, subjects underwent a HRM study performed by one of the authors listed. For each HRM study, the manometry catheter was introduced trans nasally and when the catheter tip was inserted near the depth of the esophageal inlet, the participants were asked to swallow sips of water to facilitate the passage of the catheter into the esophagus, and then it was positioned to record from hypopharynx to stomach with the three distal sensors positioned in the gastric lumen.

After successful catheter insertion to a depth of approximately $45-50 \mathrm{~cm}$, as identified by the presence of both upper and lower high-pressure zones (upper esophageal sphincter-UES and LES), the participants then assumed a supine position and were allowed five minutes for accommodation. The catheter was zeroed to intragastric pressure. Then, patients received 10 boluses of $5 \mathrm{~mL}$ of water with an interval of $20 \mathrm{~s}$. All swallows were revised by three investigators and inter-reader concordance $>90 \%$ had been established, after standardizing the reading protocol among the three readers as part of clinical governance standards in routine clinical care.

HRM data was analyzed according to the algorithm recommended by the Chicago Classification ${ }^{(10)}$. The basal and relaxation LES pressures were referenced to gastric pressure, whereas the esophageal contraction parameters and UES pressures were referenced to atmospheric pressure.

Manometric parameters of the UES (upper esophageal sphincter resting pressure, upper esophageal sphincter extension), of the esophagus body (distal contractile integral, distal contraction latency, esophageal length) and of the EGJ (LES resting pressure, integrated relaxation pressure 4-second, LES extension, EGJ contractile integral) were determined.

The UES resting pressure was automatically recorded after the placement of specific software markers on the UES outline during a period of no swallowing. The contractile deceleration point was taken as the inflection point along the $30 \mathrm{mmHg}$ isobaric contour where propagation velocity slows, demarcating the phrenic ampulla. The distal latency (DL) was defined as the interval of time between the deglutition UES relaxation and the contractile deceleration point. The distal contractile integral (DCI) was calculated by multiplying the mean pressure (amplitude) by the duration of propagation of the contractile wave front by the length of smooth muscle esophagus from the body transition zone until the distal pressure trough, excluding pressures below $20 \mathrm{mmHg}$ (FIGURE 2). Esophageal body length was defined as the distance between the lower border of the UES and the upper border of the LES.

The basal lower esophageal sphincter median respiratory resting pressure was automatically determined by placing the specific marker over the EGJ outline during a period of no swallowing. The $4 \mathrm{~s}$ integrated relaxation pressure (IRP-4s) was defined as the mean EGJ relaxation lowest cumulative pressures during $4 \mathrm{~s}$, continuous and/or separated, during a 10-second period post

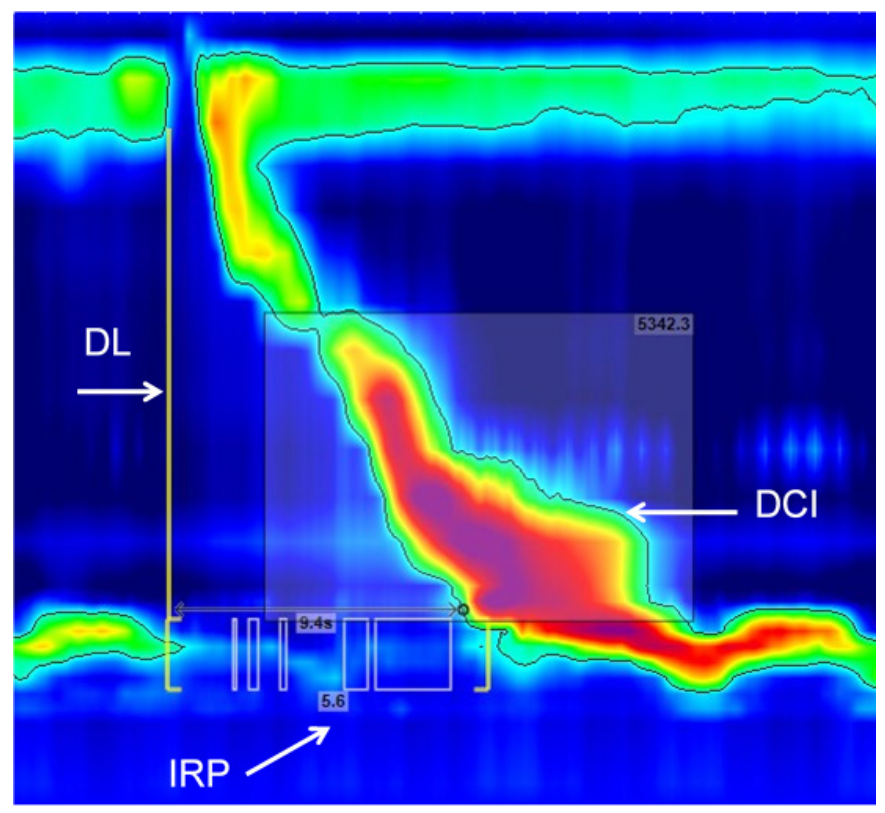

FIGURE 2. Record of a deglutition captured by high-resolution manometry water-perfused system device showing the markings of the traditional Chicago Classification parameters, isobaric contour $20 \mathrm{mmHg}$. High-resolution manometry parameters as determined by Chicago Classification. DL: distal latency; DCI: distal contractile integral; IRP: integrated relaxation pressure.

deglutition time window following the relaxation of the UES in the anatomic zone defining EGJ. The IRP is referenced to gastric pressure, while all other metrics are referenced to the atmospheric pressure. FIGURE 2.

The EGJ contractile integral (EGJ-CI) is a novel esophageal high-resolution manometry (HRM) metric that evaluates EGJ barrier function ${ }^{(11)}$. The EGJ-CI takes both inspiratory and expiratory LES pressures, and EGJ length into account, as all are fundamental to the assessment of the EGJ barrier. The landmark period was used to identify three respiratory cycles, and the duration of the cycles was recorded. The gastric baseline was determined during the landmark phase and set as the threshold for EGJ-CI calculation. The value computed with the DCI tool in mmHg.cm.s was then divided by the duration of the three respiratory cycles (in seconds) yielding EGJ-CI units of $\mathrm{mmHg} . \mathrm{cm}$. Hence, although time is not a factor in EGJ-CI units, the measure does reflect the contractility of the EGJ for a period of three respiratory cycles ${ }^{(11)}$. FIGURE 3.

To all HRM metrics was used a $20 \mathrm{mmHg}$ isobaric contour which was also used in the CC. Normative values for each of the above parameters were derived as follows:

a: The mean, median, range, and percentiles (5th and 95th) were obtained for all the above HRM metrics.

b: The percentiles used as cutoff values were:

1. IRP-4s: Less than 95th percentile.

2. DL: 5 th percentile value.

3. DCI: 5th-95th percentile.

4. DCI-CI: 5 th percentile value.

5. Peristaltic break size: 95 th percentile.

\section{Statistical analysis}

Data were expressed by measures of central tendency and dispersion. Statistical analysis was performed using SPSS version 26 


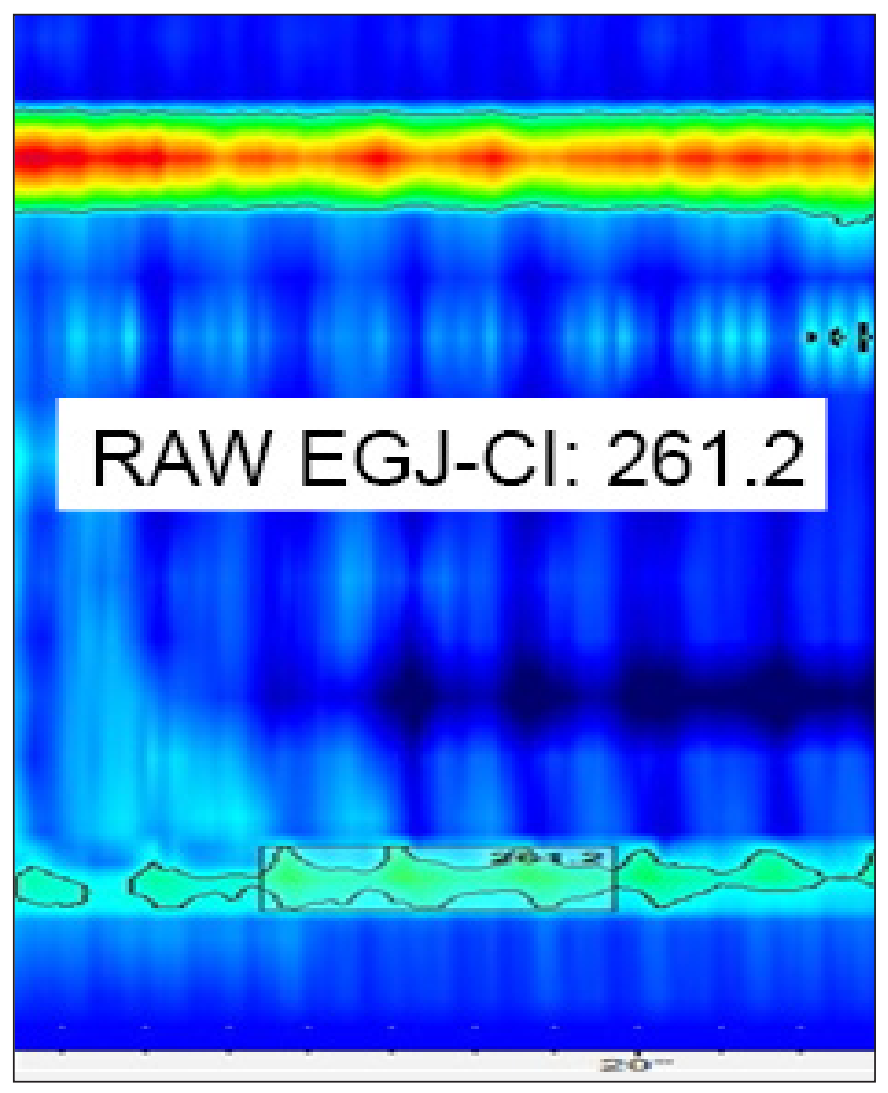

FIGURE 3. Esophagogastric junction contractile integral calculation (EGJ-CI). The EGJ-CI takes both inspiratory and expiratory lower esophageal sphincter pressures, and EGJ length into account, as all are fundamental to the assessment of the EGJ barrier. The landmark period was used to identify three respiratory cycles, and the duration of the cycles was recorded. The gastric baseline was determined during the landmark phase, and set as the threshold for EGJ-CI calculation. The value computed with the distal contractile integral tool in $\mathrm{mmHg} . \mathrm{cm}$.s was then divided by the duration of the three respiratory cycles (in seconds) yielding EGJ-CI units of $\mathrm{mmHg} . \mathrm{cm}$.
(SPSS, Inc Chicago, IL, USA). The mean value \pm SD, the median (interquartile), median and the 5 th and 95 th percentiles were calculated for each parameter. Reference values were established as the interval between the 5th and 95th percentiles of values.

\section{RESULTS}

\section{Subjects}

The HRM procedure was well tolerated by the participants of the study, 92 heathy volunteers ( 51 female and 41 male), that were enrolled for analysis. The mean age was $40.5 \pm 13.2$ years (range: 18-75years).

Measurements were successfully obtained in all subjects, and none of them met criteria for major esophageal motor disorders as stated by CC.

\section{Normative values for water-perfused HRM}

No participants had hiatal hernia. EGJ, esophageal, and UES parameters are shown in TABLE 1.

\section{EGJ}

For the mean basal pressure of the EGJ the 5th-95th percentile range was $13.7-42.4 \mathrm{mmHg}$ (range: $7.2-57 \mathrm{mmHg}$ ). For the extension of EGJ the 5th-95th range was 2.0-4.6 cm (range: $1.9-5.3 \mathrm{~cm}$ ). The 5th-95th percentile range for the IRP- $4 \mathrm{~s}$ was $4.5-15.8 \mathrm{mmHg}$ (range: $2.6-17.8 \mathrm{mmHg}$ ). For EGJ-CI the 5th-95th was 21.7-86.9 mmHg.cm.s (range: 9.8-126.1 mmHg.cm.s).

\section{Esophageal body}

The 5th-95th percentile range was 708-4,111 mmHg.cm.s for DCI (range: $464.8-6839 \mathrm{mmHg} . \mathrm{cm} . \mathrm{s}$ ), and 5.8-9.9 s for DL (range: $5.3-10.7 \mathrm{~s})$. Total break size in the esophageal contraction length was $4.0 \mathrm{~cm}$ (range: $0.1-6.8 \mathrm{~cm}$ ).

\section{UES}

The 5th-95th percentile range was $25.9-145.8 \mathrm{mmHg}$ for mean basal pressure of the UES (range: $21.3-198.3 \mathrm{mmHg}$ ), and 2.3-5.2 $\mathrm{mmHg}$ for UES extension (range: $2.0-5.7 \mathrm{~cm}$ ).

TABLE 1. EGJ parameters, esophageal parameters, and UES parameters as measured by water-perfused HRM in 92 healthy volunteers.

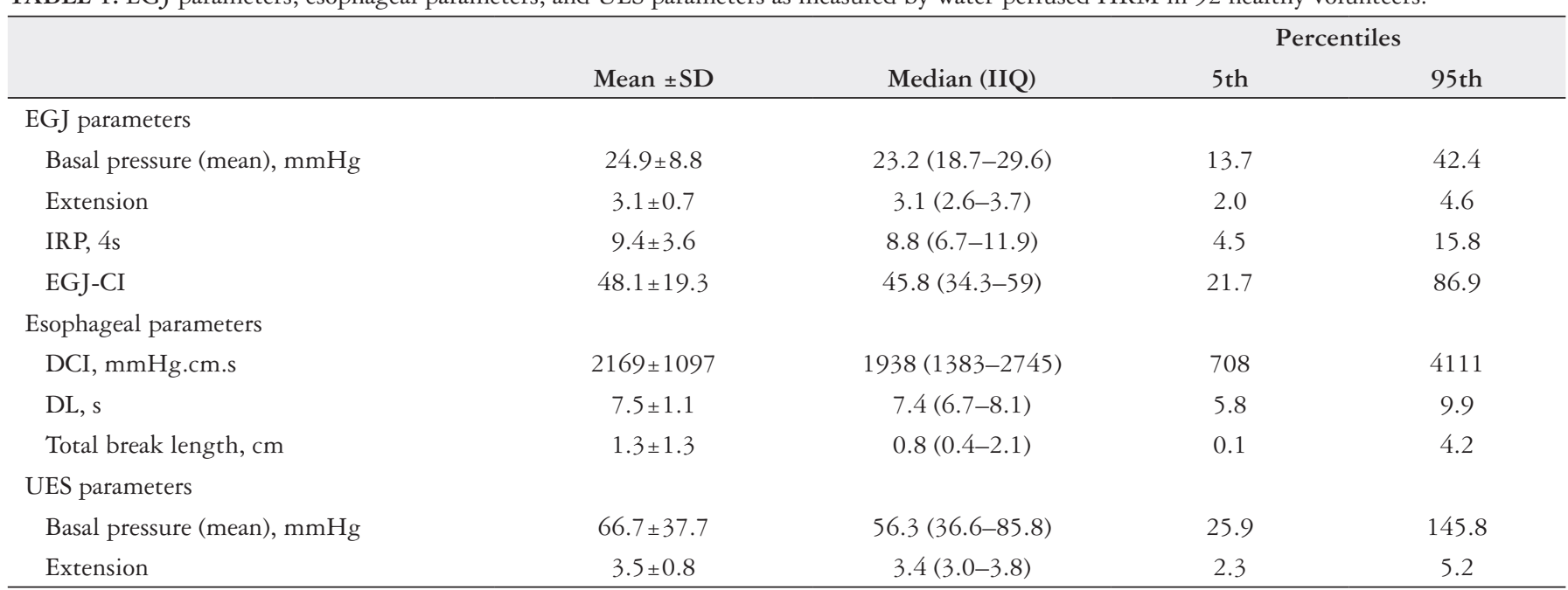

EGJ: esophagogastric junction; IRP: integrated relaxation pressure; ECJ-CI: contractile integral of esophagogastric junction; DCI: distal contractile integral; DL: distal latency; UES: upper esophageal sphincter. 
In brief, normative values for water-perfused HRM of the CC were as follow:

IRP: $<16.0 \mathrm{mmHg}$

EGJ-CI: > $22.0 \mathrm{mmHg} . \mathrm{cm}$

DCI: $700-4.100 \mathrm{mmHg} . \mathrm{cm} . \mathrm{s}$ (normal); Ineffective esophageal motility: <700.0 mmHg; Hypercontractile: $>7000.0 \mathrm{mmHg} . \mathrm{cm} . \mathrm{s}$

DL: $<6.0 \mathrm{~s}$

Peristaltic break size: $>4.0 \mathrm{~cm}$

\section{DISCUSSION}

Esophageal HRM is today considered worldwide as a first class exam. The CC 3.0 for esophageal motility disorders is based on a set of normative values for key metrics that was obtained using one of the commercially available HRM devices ${ }^{(10)}$. Thus, it is of great importance to evaluate whether these normative values can be used for different HRM devices as well. It should be considered that numerous factors including the type of HRM system, demographic factors, catheter diameter, body position during testing, consistency of bolus swallows, and esophageal length have an influence on the normative data ${ }^{(12)}$. On the other hand, there are HRM different systems and types of catheters commercially available that should have their results clinically evaluated as HRM has becoming an important tool to approach esophageal motor disorders.

HRM systems led to the establishment of new parameters specially to study the EGJ and esophageal body and hence new algorithms of analysis ${ }^{(10)}$. In this regard, HRM water-perfused systems deserve some additional comments related to limitations and advantages such as set up and preparation of the device is more time-consuming and pressure responses rates are slower compared do solid-state systems. On the other hand, as catheters of the waterperfused systems tend to be more durable and comfortable and even cheaper than the solid-state devices ${ }^{(12)}$, the HRM water-perfused devices are widely used in emerging countries like Brazil. In this regard, it should be mention a prospective, randomized, double blind, crossover study comparing the tolerability and procedure duration of a 36-channel solid-state system (Given Imaging, Los Angeles, CA, USA) with that of a 24-channel water-perfused system (EB Neuro, Firenze, Italy) in 20 healthy volunteers ${ }^{(13)}$. No difference in tolerability between the two systems was observed. Although the water-perfused procedure required a significantly higher set-up and analysis time compared to the solid-state HRM, no difference between the two was observed in terms of tracing acquisition time ${ }^{(13)}$.

The spatial resolution of the catheter used on our HRM waterperfused system was $2 \mathrm{~cm}$ spacing in esophageal body and $0.7 \mathrm{~cm}$ spacing in EGJ zone (7 cm segment). It is an important issue as spatial resolution could have an effect on the $\mathrm{CC}$ metrics and diagnosis. De Schepper et al. ${ }^{(14)}$ conducted a study in 20 healthy volunteers and 47 patients with upper gastrointestinal symptoms and they reanalyzed HRM studies of the esophagus using the original $1 \mathrm{~cm}$ spacing in the segments outside the $7 \mathrm{~cm}$ EGJ segment, and again after manually increasing the spacing between sensors to 2,3 , and $4 \mathrm{~cm}$ above the LES region. There was a very strong correlation between the $1 \mathrm{~cm}$ and $2 \mathrm{~cm}$ analysis for all Chicago metrics studied in healthy volunteers and the $2 \mathrm{~cm}$ spacing analysis also correlated very well with the $1 \mathrm{~cm}$ analysis for the different Chicago diagnoses obtained in the patients. Thus, the same normal values of CC can be used when catheters with a slightly lower resolution are used ${ }^{(14)}$. Therefore, considering these data, we assume that our 24-channel water-perfused catheter with its unique spiral configuration to study EGJ region with sensors spaced $7 \mathrm{~cm}$ and spaced $2 \mathrm{~cm}$ apart in the area of the esophageal body is a reliable configuration to establish normal values.

The ECJ contractile integral is a novel HRM tool designed to assess EGJ barrier function, which incorporates an intragastric pressure reference and the respiratory cycle to assess the barrier function of the EGJ ${ }^{(15)}$. Reduced EGJ-CI was initially reported to be associated with gastroesophageal reflux disease ${ }^{(15)}$. A greaterthan-normal EGJ-CI was reported in patients with newly diagnosed achalasia $^{(16)}$ and, recently, this metric of EGJ has been used to assessment of treatment response in achalasia ${ }^{(17)}$. To the best of our knowledge, this study is the first prospective work with HRM water-perfused manometry that assessed EGJ-CI normative values (TABLE 1).

Some handicaps were found in the study of UES opening and its residual pressure. Since the UES is composed of striated muscle, pressure changes are more rapid than pressure changes in the esophageal body or in the EGJ. The slower response rate of HRM water-perfused is likely the cause of the large differences and poor agreement between the UES residual pressure as measured by solid-state $\mathrm{HRM}$ and water-perfused $\mathrm{HRM}^{(9)}$. Another reason for differences in UES parameters might be the existence of the pharyngo-UES reflex. It has been shown that both rapid and continuous slow perfusion of the pharynx with water can increase UES pressure $^{(9)}$. For these reasons, we believe that HRM water-perfused might overestimate UES resting pressure and UES relaxation pressure and, consequently, water-perfused HRM is not appropriate to measure residual pressure of the UES.

In our study, like others ${ }^{(6,8,12,18-23)}$, normal values were defined, dependent on what parameter studied, by the 5th and/or 95th percentile obtained in a population of healthy volunteers. Keeping in mind that this statistical analysis of results can induce, depending on the parameter, to a false abnormal result, simply by chance $(5 \%$ or $10 \%)$. The maximal DCI of the healthy individuals in this study was $6839 \mathrm{mmHg}$.cm.s in water swallows, so 7000.0 $\mathrm{mmHg} . \mathrm{cm}$.s is probably the proper threshold of the DCI for the diagnosis of hypercontractile swallow in this studied population. Jackhammer esophagus diagnosis can be proposed as DCI $>7000.0 \mathrm{~m}$ $\mathrm{mmHg} . \mathrm{cm} . \mathrm{s}$ in $\geq 2$ swallows. In this regard, data must be interpreted carefully by physicians, always in the context of the clinical presentation, to avoid judgment biases.

In our study DCI values were lower than those in CC $3.0^{(10)}$. One explanation for this discrepancy is that we used intragastric pressure as zero value, as opposed to atmospheric pressure when solid state catheters are used ${ }^{(24)}$, and in this study, intragastric pressure was $5 \mathrm{mmHg}$. Another explanation, we supposed to be a slower increase in pressures due to higher complacency of our system. This can also explain the longer DL.

Kuribayashi et al. ${ }^{(25)}$ studied a Japanese population and used DCI $>10,000 \mathrm{mmHg} . \mathrm{cm} . \mathrm{s}$ as threshold for hypercontractile contraction and $<1,000 \mathrm{mmHg}$.cm.s as threshold for weak contraction. In the present work, we suggest a DCI $<700.0 \mathrm{mmHg} . \mathrm{cm}$.s to define weak contraction, and in $\geq 50 \%$ of swallows to define ineffective esophageal motility. We must be careful in this respect, since the threshold of $<450 \mathrm{mmHg} . \mathrm{cm} . \mathrm{s}$ in CC 3.0 was not derived from their data but is a number that roughly correlates with an amplitude $<30 \mathrm{mmHg}$ in conventional manometry. Thus, this topic deserves further studies.

Recently, Da Silva et al. ${ }^{(18)}$ published a Brazilian unicenter 
cohort study to evaluate normative values for HRM that used the same water-perfused device as ours, but with some differences in the protocol study as long as the number of volunteers were significantly smaller, catheter configuration was different, and subjects underwent HRM with the test performed in left lateral decubitus that probably concurred to some discrepancies observed in IRP-4s, DL and DCI calculation.

Routinely the esophageal motility function is tested with liquid bolus swallows. Although there are efforts to improve esophageal motility testing and diagnosis with solid bolus swallows ${ }^{(19,23,26)}$, lack of standardization of the method and appropriate algorithm analysis preclude its use in clinical practice. As such, in the present study only liquid bolus swallows to determine normative values, were used.

The analysis of the results of normative values among various different configuration catheters for HRM water-perfused systems including our study (TABLE 2), shows some discrete discrepancies for the most relevant CC HRM parameters and reinforce the need to set normal values for each device configuration in order to support the use of this technique in the diagnostic work-up of patients with dysphagia amongst others. However, the usefulness of normal values is always determined by the likelihood that an abnormal value can indeed be considered pathological and responsible for symptoms ${ }^{(12)}$, and in this context, clinical evaluation continue to be an important issue in decision making. Esophageal HRM is an evolving method and the next version (4.0) is expected to include a new protocol, recommending routine provocative testing prior to surgical fundoplication ${ }^{(27)}$.

While the strength of our study is the cohort size, its limitations include lack of subjects in extremes of age. Furthermore, the waterperfused system was not compared head-to-head with a solid-state system due to high cost issues.

In conclusion, this is the first multicenter study that reported esophageal normative data in supine posture for the 24-channel water-perfused HRM system, the most common used in Brazil. Appropriated modifications of CC cutoff values were made and the normal values proposed here are slightly different from previously obtained normal values ascertained by other HRM water-perfused systems. The presented normal values actually helps the physicians to use this HRM water-perfused in clinical practice and to define their normal and abnormal values.

The results of our study also confirm that differences in measurement outcome exist between different systems and that normal values must be determined for each different manometric system. It is essential an effort from others motility labs worldwide, using the various esophageal HRM systems configurations, to publish their data in order to validate normative values and make the valuable $\mathrm{CC}$ relevant for all.

\section{Authors' contribution}

Domingues GR, Michelsohn NH, Viebig RG: conception and design of the study, data interpretation, critical revision of manuscript, data collection, text writing. Chinzon D, Moraes-Filho JPP: critical revision of manuscript, text writing. Nasi A, Andrade CG, Lemme EM, Abrahão Junior LJ, Bravim MG, Nobre e Souza M, Carvalho NS, Carvalho PJPC, Rodrigues TN: data collection.

\section{Orcid}

Gerson Ricardo Domingues: 0000-0003-0431-451X.

Nelson Henrique Michelsohn: 0000-0003-3394-7172.

Ricardo Guilherme Viebig: 0000-0002-6541-0401.

Décio Chinzon: 0000-0003-3030-6687.

Joaquim Prado P Moraes Filho: 0000-0003-1280-6047.

Ary Nasi: 0000-0001-6928-4281.

Carla Granja Andrade: 0000-0002-5859-0539.

Eponina Maria Lemme: 0000-0002-1916-9274.

Luiz João Abrahão Junior: 0000-0003-2107-2460.

Mauricio Gustavo Bravim: 0000-0002-6268-4060.

Miguel Ângelo Nobre e Souza: 0000-0003-3446-739X.

Nayara Salgado Carvalho: 0000-0001-9167-8957.

Paulo J P C Carvalho: 0000-0002-9041-8835.

Tomás Navarro Rodrigues: 0000-0002-3458-699X.

TABLE 2. Studies of normative values reported for supine posture in healthy volunteers using water-perfused systems.

\begin{tabular}{|c|c|c|c|c|c|c|c|c|}
\hline \multirow{3}{*}{ Study } & \multirow{3}{*}{$\begin{array}{l}\text { Catheter } \\
\text { (channels) }\end{array}$} & Diameter & $\mathrm{n}$ volunteers & BERP & IRP-4s & DCI & DL & ECJ-CI \\
\hline & & \multirow[t]{2}{*}{$(\mathrm{cm})$} & \multirow[t]{2}{*}{ (Country) } & (5th-95th) & ( mmHg) & (5th-95th) & (5th) & $\begin{array}{l}\text { (5th) } \\
\text { mmHg.cm.s }\end{array}$ \\
\hline & & & & $\mathrm{mmHg}$ & & mmHg.cm.s & $\mathbf{s}$ & \\
\hline Current study & 24 perfusion & 4.7 & 92 (Brazil) & $13.7 / 42.4$ & 15.8 & $708-4111$ & 5.8 & 21.7 \\
\hline Silva/Herbella ${ }^{(18)}$ & 24 perfusion & 4.7 & 32 (Brazil) & $4.9 / 37$ & 16 & $83-3837$ & 6.2 & - \\
\hline Srinivas $^{(20)}$ & 16 perfusion & 3.5 & 53 (India) & $4.4 / 37.6$ & 13 & $72-3276$ & 4.6 & - \\
\hline Burgos-Santamaria $^{(6)}$ & 22 perfusion & 4 & 16 (Spain) & $5 / 54$ & 20 & $285-2820$ & 6.1 & - \\
\hline Tseng $^{(21)}$ & 22 perfusion & 4.2 & 66 (Taiwan) & $8.7 / 46.5$ & 20 & $99-2816$ & 6.2 & - \\
\hline Capovilla $^{(13)}$ & 24 perfusion & - & 20 (Italy) & $4 / 34.3$ & 8.8 & $557-1726$ & 7 & - \\
\hline Kessing $^{(8)}$ & 36 perfusion & 4.7 & 50 (Holland) & $3 / 29.8$ & 18.8 & $142-3674$ & 6.2 & - \\
\hline
\end{tabular}

BERP: basal EGJ respiratory pressure; IRP-4s: integrated relaxation pressure; DL: distal latency; DCI: distal contractile integral; ECJ-CI: contractile integral of esophagogastric junction. 
Domingues G, Michelsohn NH, Viebig RG, Chinzon D, Moraes-Filho JPP, Nasi A, Andrade CG, Lemme EM, Abrahão-Junior LJ, Bravim MG, Nobre-e-Sousa MA, Carvalho NS, Carvalho PJPC, Rodrigues TN. Valores normais da manometria de alta resolução de esôfago: estudo multicêntrico brasileiro. Arq Gastroenterol. 2020;57(2):209-15.

RESUMO - Contexto - A manometria de alta resolução tem sido um avanço significativo nos diagnósticos esofágicos. Existem diferentes tipos de cateteres e sistemas dispositivos para capturar pressões esofágicas que geram dados variáveis relacionados à Classificação de Chicago (CC) e, consequentemente, podem influenciar os resultados de valores da normalidade. Não há dados normativos com voluntários saudáveis na postura supina, para o sistema manométrico sob perfusão em água de 24 canais, o mais utilizado no Brasil. Objetivo-Determinar os valores normativos manométricos do esôfago para um cateter sob perfusão de alta resolução de 24 canais na postura supina utilizando-se voluntários saudáveis assintomáticos de acordo com os parâmetros CC. Métodos - Um total de 92 voluntários sem sintomas gastrointestinais ou medicamentos que afetassem a motilidade gastrointestinal foram submetidos à manometria de alta resolução do esôfago por protocolo padrão (Sistema Alacer Multiplex). Foram coletados parâmetros de idade, sexo e os da manometria analisados pelo software Alacer versão 6.2. A mediana, os limites, e 5\% e 95\% percentis (quando aplicável) foram obtidos para todas as métricas de alta resolução. Os valores normais foram definidos como percentis de $95 \%$ da integral da pressão de relaxamento (IRP), $5 \%-100 \%$ da integral contrátil distal (DCI), e 5\% latência distal. Resultados - A média de idade foi de 40,5 $\pm 13,2$ anos. As métricas normativas foram definidas como IRP $<16 \mathrm{mmHg}$ ) e DCI (708-4111 mmHg.cm.s). Para a latência distal foi de 5,8-9,9 s (faixa: 5,3-10,7s). O comprimento total de quebra na contração esofágica foi de 4,0 cm (faixa: 0,1-6,8 cm). Para a EGJ-CI a faixa 5\%-95\% percentis foi de 21,7-86,9 mmHg.cm.s. Conclusão - Este é o primeiro relatório de dados normativos para o sistema de 24 canais perfundido por água na postura supina. A partir dos dados encontrados observa-se a possibilidade de alterar os cortes CC 3.0 para este sistema. Observa-se que há uma tendência que DCI $>7000 \mathrm{mmHg} . \mathrm{cm}$.s possa representar o limite inferior da hipercontratilidade e quando $<700 \mathrm{mmHg} . \mathrm{cm} . \mathrm{s}(<5 \%$ percentil) interpretada como motilidade esofágica ineficaz ou contração falha. Também em comparação com Chicago 3.0, foi encontrada maior pressão de relaxamento integrado e duração da latência distal. Ressaltamos que esses dados devem ser confirmados por estudos futuros.

DESCRITORES - Esôfago. Motilidade gastrointestinal. Manometria. Peristaltismo. Valores de referência.

\section{REFERENCES}

1. Niebisch S, Wilshire CL, Peters JH. Systematic analysis of esophageal pressure topography in high-resolution manometry of 68 normal volunteers. Dis Esophagus. 2013;26:651-60

2. Zavala-Solares MR, Saleme E, Vargas-Vorackova F, Valdovinos MA. High-resolution esophageal pressure topography (HREPT) in asymptomatic volunteers. A comparative study between solid-state and water-perfused systems. Gastroenterology. 2012;142(Suppl 1):S-239.

3. Jakubowicz M, Wienbeck M, Barnert J. Device dependent problems in esophageal manometry. Dig Dis Sci. 1991;36:25S-28S.

4. Xiang X, Tu L, Zhang X, Xie X, Hou X. Influence of the catheter diameter on the investigation of the esophageal motility through solid-state high-resolution manometry. Dis Esophagus. 2013;26:661-7.

5. Pandolfino JE, Ghosh SK, Zhang Q, Jarosz A, Shah N, Kahrilas PJ. Quantifying EGJ morphology and relaxation with high-resolution manometry: a study of 75 asymptomatic volunteers. Am J Physiol Gastrointest Liver Physiol. 2006;290:G1033-40.

6. Burgos-Santamaría D, Marinero A, Chavarría-Herbozo CM, Teresa Pérez-Fernández T, López-Salazar TR, Santander. Normal values for water-perfused esophageal high-resolution manometry. Rev Esp Enferm Dig. 2015;107:354-8.

7. Wang K, Duan LP, Ge Y, Xia ZW, Xu ZJ. A comparative study of 22-channel water-perfusion system and solid-state system with 36 -sensors in esophageal manometery. BMC Gastroenterol. 2012;12:157-60.

8. Kessing BF, Weijenborg PW, Smout AJ, Hillenius S, Bredenoord AJ. Water-perfused esophageal high-resolution manometry: normal values and validation. Am J Physiol Gastrointest Liver Physiol. 2014;306:G491-5.

9. Ghosh SK, Pandolfino JE, Zhang Q, Jarosz A, Shah N, Kahrilas PJ. Quantifying esophageal peristalsis with high resolution manometry: a study of 75 asymptomatic volunteers. Am J Physiol Gastrointest Liver Physiol. 2006;290:G988-97.

10. Kahrilas PJ, Bredenoord AJ, Fox M, Gyawali CP, Roman S, Smout AJPM, Pandolfino JE \& International High Resolution Manometry Working Group. The Chicago Classification of esophageal motility disorders, v3.0. Neurogastroenterol Motil. 2015;27:160-74.

11. Nicodème F, Pipa-Muniz M, Khanna K, Kahrilas PJ, Pandolfino JE. Quantifying esophagogastric junction contractility with a novel HRM topographic metric, the EGJ-Contractile Integral: normative values and preliminary evaluation in PPI non-responders. Neurogastroenterol Motil. 2014:26:353-60.

12. Herregods TVK, Roman S, Kahrilas PJ, Smout AJPM, Bredenoord AJ. Normative values in esophageal high-resolution manometry. Neurogastroenterol Motil. 2015; 27:175-87

13. Capovilla G, Salvador R, Savarino E, Nicoletti L, Zaninotto G, Costantini M. Comparative assessment of tolerability, duration and costs of solid-state vs. water-perfused system for esophageal motility testing - Data from a prospective, randomized, double blind, crossover study. Digestive Disease Week; 03/05/2014; Chicago, 2014

14. De Schepper HU, Kessing BF, Weijenborg PW, Oors JM, Smout AJ, Bredenoord AJ. Impact of spatial resolution on results of esophageal high-resolution manometry. Neurogastroenterol Motil. 2014;26:922-8.
15. Nicodeme F, Pipa-Muniz M, Khanna K, Kahrilas PJ, Pandolfino JE. Quantifying esophagogastric junction contractility with a novel HRM topographic metric, the EGJ-Contractile Integral: normative values and preliminary evaluation in PPI non-responders. Neurogastroenterol Motil. 2014;26:353-60.

16. Wang D, Xu H, Tang T, Wang J, YU Y, Gyawali CP. Assessment of the esophagogastric junction (EGJ) using the EGJ contractile integral (EGJ-CI) following per-oral endoscopic myotomy (POEM) in achalasia. Rev Esp Enferm Dig. 2018;706-11.

17. Carlson DA, Lin Z, Kahrilas PJ, Sternbach J, Hungness ES, Soper NJ, Balla M, Listernick Z, Tye M, Ritter K, Craft J, Ciolino JD, Pandolfino JE. High-Resolution impedance manometry metrics of the esophagogastric junction for the assessment of treatment response in acalasia. Am J Gastroenterol. 2016;111:1702-10.

18. Da Silva RMB, Herbella FAM, Gualberto D. Normative values for a new water-perfused high resolution manometry system. Arq Gastroenterol. 2018;55(Suppl 1):30-4.

19. Xiang X, Wang A, Tu L, Xie X, Ke M, Yang Y, et al. The differences in the esophageal motility between liquid and solid bolus swallows: A multicenter high-resolution manometry study in Chinese asymptomatic volunteers. Neurogastroenterol Motil. 2019;31:e13574.

20. Srinivas M, Jain M, Bawane P, Jayanthi P. Chicago Classification normative metrics in a healthy Indian cohort for a 16-channel water-perfused high-resolution esophageal manometry system. Neurogastroenterol Motil. 2018;30:e13386.

21. Tseng PH, Wong RKM, Wu JF, Chen CC, Tu CH, Lee YC, et al. Normative values and factors affecting water-perfused esophageal high-resolution impedance manometry for a Chinese population. Neurogastroenterol Motil. 2018;30:e13265.

22. Weijenborg PW, Kessing BF, Smout AJPM, Bredenoord AJ. Normal values for solid-state esophageal high-resolution manometry in a European population; an overview of all current metrics. Neurogastroenterol Motil. 2014;26:654-9.

23. Xiang XL, Wang A, Tu L, Ke MY, Yang YS, Jiang B, et al. The motility of esophageal sphincters during liquid and solid bolus swallows: a multicenter normative value study of high-resolution manometry in China. Neurogastroenterol Motil. 2017;29:e12914

24. Bogte A, Bredenoord J, Oors J, Siersema PD, Smout AJPM. Normal values for esophageal high-resolution manometry. Neurogastroenterol Motil. 2013 25:762-e579.

25. Kuribayashi S, Iwakiri K, Shinozaki T et. al Clinical impact of different cut-off values in high-resolution manometry systems on diagnosing esophageal motility disorders. J Gastroenterol. 2019;12:1078-82.

26. Sweis R, Anggiansah A, Wong T, Kaufman E, Obrecht S, Fox M. Normative values and inter-observer agreement for liquid and solid bolus swallows in upright and supine positions as assessed by esophageal high-resolution manometry. Neurogastroenterol Motil. 2011;23:509-e198.

27. Hasak S, Brunt LM, Wang D, Gyawali CP. Provocative tests on esophageal high-resolution manometry prior to surgical fundoplication: expanding the manometry protocol. Clin Gastroenterol Hepatol. 2020 Jan 9. pii: S15423565(20)30030-6. doi: 10.1016/j.cgh.2020.01.002. [Epub ahead of print]. 
In article Normal values of esophageal high-resolution manometry: a Brazilian multicenter study, DOI: 10.1590/S0004-2803.20200000040, published in journal Arq Gastroenterol. 2020;57(2):209-15, in page 209:

\section{Which was read}

Results: The mean age was $40.5 \pm 13.2$ years. Our normative metrics were integrated relaxation pressure $<16 \mathrm{mmHg}$ and distal contractile integral (708-4111 mmHg.cm.s) distal latency was $<6 \mathrm{~s}$ and peristaltic break size $(>4 \mathrm{~cm})$.

\section{Read}

Results: The mean age was $40.5 \pm 13.2$ years. Our normative metrics were integrated relaxation pressure $<16 \mathrm{mmHg}$ and distal contractile integral (708-4111 mmHg.cm.s) distal latency was $<6 \mathrm{~s}$ and peristaltic break size $(<4.0 \mathrm{~cm})$.

And page 213:

Which was read

Peristaltic break size: $>4.0 \mathrm{~cm}$

\section{Read}

Peristaltic break size: $<4.0 \mathrm{~cm}$ 